\title{
Analysis of experience of the use of plastic cannulas in Spanish haemodialysis units
}

\author{
Guillermo Pedreia-Robles ${ }^{1}$, Yaiza Martínez-Delgado ${ }^{1}$, Cristina Herrera-Morales ${ }^{1}$, \\ Ana Vasco-Gómez ${ }^{1}$, Ernestina Junyent-Iglesias ${ }^{1}$.
}

\author{
${ }^{1}$ RN, BScN, MSN. Nephrology Department. Parc de Salut Mar. Barcelona. Spain. \\ Correspondence: \\ Guillermo Pedreira-Robles. \\ Nephrology Department. Parc de Salut Mar. Barcelona. Spain. \\ Passeig Marítim 25-29. 08003. Barcelona. Spain. \\ Mail: gpedreira@parcdesalutmar.cat
}

\section{DECLARATIONS}

\section{Funding}

This study, once finished, was awarded the second prize for the best abstract on needling with plastic cannulae, with an endowment of $€ 500$, at the 48th EDTNA/ERCA International Conference and was supported by Medtronic.

\section{Conflict of interests}

None.

\section{Acknowledgement}

To Silvia Esteban-Sepúlveda for her support in the study design, Juan Carlos Medina-Alcaraz for his support in the data analysis, Tai Mooi Ho-Wong and Gail Craigie for their support in the translation process and to the Spanish nephrology nurses for their participation in the survey.

\section{Author contributions}

GPR: Principal investigator, participated in the study design, supervised data collection and analysis, helped draft the manuscript, and approved the final manuscript. YMD, CHM, AVG and EJI: Participated in the study design, participated in data collection and analysis, helped draft the manuscript, and approved the final version. 


\title{
Analysis of experience of the use of plastic cannulas in Spanish haemodialysis units
}

\begin{abstract}
Introduction: Plastic cannulas (PC) have shown efficacy in haemodialysis (HD) and are presented as a positive innovation for patients and vascular access survival.
\end{abstract}

Objective: To analyse Spanish HD nurses' experience of using PC.

Design: Cross-sectional observational study.

Methods: An ad hoc questionnaire was administered on nurses' experience of PC use.

Results: A total of 163 Spanish HD nurses were surveyed, of whom $42.3 \%$ had PC in their workplace and 50.9\% had used them. In all, 55.8\% had received training and $77.9 \%$ wished to receive more training. These needles were significantly more available in public institutions than in private centres $(p<0.001)$. There was no significant difference between years of experience and having received training $(p=0.915)$. There was a moderate-strong correlation $(r h o=0.659)$ between greater professional satisfaction with the product and greater patient satisfaction $(p<0.001)$. The nurses would make a median of two $\left[\mathrm{P}_{25} 1 ; \mathrm{P}_{75} 3\right]$ modifications in the product design. The characteristics of the PC were rated positively by $55.8 \%$ and negatively by $10.3 \%$.

Conclusions: A substantial proportion of the nurses surveyed did not use PC and had not received training in their use. Respondents reported that PC could be improved and a small percentage perceived them negatively.

Implications for practice. Based on the evidence presented and available, if we manage to integrate this knowledge and work on the continuum of achieving excellence, we will continue to grow as a profession and provide higher quality care.

Key words: chronic kidney disease, haemodialysis, plastic cannula, product evaluation. 


\section{INTRODUCTION}

Haemodialysis (HD) treatment is one of the lifelines of people with CKD. An essential requirement for optimal HD is adequate vascular access (VA). Ideal VA must allow a safe and continuous approach to the vascular system, provide sufficient blood flow, and be free from complications (Ibeas et al. 2017). The VA of choice for patients in HD programmes is native arteriovenous fistula, since it has a lower complication rate and higher survival rate than arteriovenous graft and central venous catheters (Nalesso et al. 2018).

The need to insert two needles for each HD treatment causes both mechanical and haemodynamic damage, which can result in VA complications, such as extravasation of the vessel (during cannulation or the HD session); the formation of bruises, increasing the risk of thrombosis; and vessel narrowing due to intimal hyperplasia, with consequent vessel stenosis or the formation of long-term aneurysms (Smith \& Schoch 2016). Therefore, good care and management of VA is essential. Nurses play an essential role in this task, since adequate needle insertion, as well as the use of a suitable needle gauge, prevent the onset of complications, affecting the longevity of VA and the quality of HD treatments (Parisotto et al. 2014).

\section{Literature review}

For decades, most European countries have used traditional silicone metal needles as the VA approach. Recently, new puncture cannulas have been introduced. These are plastic cannulas (PC), with excellent results (National Kidney Foundation 2016). This kind of needle is characterised by being composed of a fluoroplastic catheter, which consists of an external plastic cannula and an internal metal needle or retainer that is removed once the vessel is canalised. In addition, these needles are equipped with an antireflux valve, which prevents the reflux of blood during the connection or disconnection process, providing greater safety for both the health professional and the patient. The main advantage of this product, compared with metal needles, is the lower risk of damage to the inner vessel wall or needle infiltration due to its design. By not leaving any sharp part in the vessel, it allows greater mobility of the patient's limb, which is important for patients who cannot tolerate immobilisation during the session. In addition, this kind of needle avoids accidents due to their safety system and can be used to cannulate fragile 
VA with tortuous segments or irregular depths. This can increase the number of potential puncture sites (National Kidney Foundation 2016).

Following these arguments, the benefits of PC have been amply demonstrated influencing in the quality of care provided. PC allow the cannulation of the VA after $<10$ days of its creation thus avoiding maturation time and/or the placement of a central venous catheter. As well, this opportunity allows to introduce the treatment in a planned and incremental way, using lower flows and less treatment time. This planned option avoids the start of treatment in emergency situations and with a poor general condition of the person. In addition, the residual urine of the person is also preserved, providing benefits for the treatment itself and a possible future kidney transplant (Shi, Jiang \& Wakabayashi 2020; Fulker et al. 2017).

At this moment, we should also mention that the procedure for inserting PC differs considerably from that of conventional metal needles. This can lead to difficulties for the nurses, who require training and special skills to modify the needle insertion technique (Marticorena et al. 2018). The existing data in the literature do not provide accurate indications about the type of device that should be used for each VA and, therefore, the choice is determined by the needs of each workplace, the availability of the device, and on nurses' experience or training (Parisotto et al. 2016). Moreover, a review of the literature reveals that the opinions of the nursing staff on the use of this product have not been explored. Therefore, the main objective of this study was to analyse the nurses' experience using PC in the Spanish HD units.

\section{METHODS}

\section{Design}

We conducted a cross-sectional observational study including questionnaire responses from haemodialysis nurses across Spain.

\section{Participants}

The study included 163 nurses specialised in HD from different units in Spain.

Inclusion criteria consisted of being a qualified nurse currently working in a HD service in Spain and wishing to participate voluntarily in the study.

Exclusion criteria consisted of being a nurse who formed part of the research team or who had some connection with the industry producing the product to be analysed. 


\section{Methodology}

For data collection, an ad hoc questionnaire was designed (Appendix 1), based on the literature review. The design was adapted to the objectives of this study and included closed questions with multiple response options. The content validity of the questionnaire was established by a comprehensive review of the literature and a review by experts in the field. The elements reviewed were language clarity, ease of use, the relevance of the questionnaire for professionals, and its appropriateness for the objectives of the study.

Before the questionnaire was finally disseminated, a pilot test was carried out in the HD unit of the workplace performing the study. The pilot test included a sample of 10 participants to validate the questionnaire internally, check the suitability and clarity of the language, and detect errors or comprehension difficulties. The questionnaires were delivered directly by the research group during workdays. There were no substantial changes in this phase of the validation of the questionnaire and consequently the responses were included in the final results of the study.

The final questionnaire consisted of a section with sociodemographic variables (age, sex, province, type of work institution, and years of experience in HD), and a series of questions on experience of the use of PC (Appendix 1).

The questionnaire was distributed with digital support through the Google Formulary platform to reach a greater number of nephrology nurses at the national level. We proceeded with a snowball sampling method through the research team's contacts, requesting collaboration in disseminating the questionnaire, guaranteeing at all times willingness to participate by obtaining written informed consent and the confidentiality of the responses according to current legal regulations (see ethical considerations section).

\section{Analysis}

The results were recorded and analysed through a database created by the research team with the statistical software SPSS 23 (IBM Corp.).

For the data analysis, a descriptive analysis of the sociodemographic variables and the results of the questionnaire was carried out, showing frequency distributions for qualitative variables and mean and standard deviation for quantitative variables. The chisquare test was used to compare the distribution of observations between the levels of the variables with Cramer's $V$ as a measure of the effect size. $P$ values less than 0.05 were considered statistically significant. For Cramer's $V$, values lower than 0.1 were considered 
as null for the effect size, values between 0.1 and 0.29 were considered small for the effect size, values between 0.3 and 0.49 as medium, and those equal to or greater than 0.5 as large for the effect size. The Spearman correlation was used to estimate the association between the satisfaction variables.

\section{Ethical considerations}

Informed consent was obtained online from participants prior to the distribution of the questionnaires. The tool used to distribute the questionnaires (Google Formulary) allows confidential treatment of data according to current legislation and informs respondents of this fact.

This project was approved by the Research Ethics Committee of the study researchers' centre (number 2019/8701/I) and was conducted in accordance with the basic principles guiding healthcare and research in the field of social health. Data confidentiality was guaranteed in accordance with the European Regulation 2016/679 on data protection (European Parliament 2016) and the organic law on data protection and guarantee of digital rights of Spain (Boletín Oficial del Estado 2018).

\section{RESULTS}

A total of 163 nursing professionals from different HD units in Spain were included in the study. The sociodemographic characteristics of the sample are shown in Table 1.

A total of $42.3 \%(n=69)$ of surveyed nurses reported that PC were available in their workplace and $50.9 \%(n=83)$ had used them at some time. More than half $(55.8 \%[n=91])$ had received formal training on the use of PC, with training being understood as the ability to use the product effectively. Of the 91 professionals who had received training, $19.6 \%(n=32)$ received external training (i.e. in another institution or in a workshop at a congress). The remaining $36.2 \%(n=59)$ reported they had received training in their organisation. This training was provided by an industry representative in $28.8 \%(n=47)$, by an expert nurse in $8 \%(n=13)$, and by a colleague from the same workplace in $18.4 \%$ $(n=30)$. In all, $0.6 \%(n=1)$ reported being self-taught. Three quarters of participants (77.9\% [ $\mathrm{n}=127])$ reported they would like more training in PC.

The chi-square test revealed significant difference between the type of workplace and the availability of PC ( $\mathrm{p}=0.044)$. PC were more frequently available in public institutions. Despite this significant difference, a small effect size was found according to the Cramer 
$V$ coefficient $(V=0.196)$. There was also a statistically significant relationship between having PC in the workplace and having experience of their use $(\mathrm{p}<0.001)$ with a large effect size $(V=0.767)$. There was also a statistically significant difference between the availability of PC in the workplace and having received training in their use $(\mathrm{p}<0.001)$, with a medium effect size ( $V=0.362)$. There was no significant difference between length of professional experience and the training received $(p=0.915)$ with a null effect size $(V=0.033)$.

Nurses' satisfaction with the use of PC and their perception of patient satisfaction with these needles is presented in Table 2. The Spearman bivariate correlation showed there was a high correlation $(r h o=0.659)$ between the two variables studied $(\mathrm{p}<0.001)$, indicating that patient satisfaction was directly proportional to professional satisfaction with the product; i.e., the greater the professional satisfaction, the greater the patient satisfaction perceived by the professional.

The next part of the questionnaire, based on the characteristics and knowledge of PC, is presented in Table 3, Table 4, Table 5 and Table 6.

Nurses who had used PC at some time $(50.9 \% ; \mathrm{n}=83)$ would make a median of $2\left[\mathrm{P}_{25} 1\right.$; $\mathrm{P}_{75} 3$ ] modifications to the product design. The results for this part of the questionnaire are shown in Table 3, presenting the points identified by nurses as showing room for improvement. These areas concerned the need to incorporate wings into the cannula $(74.7 \% ; n=62)$, the need to incorporate a clamping system $(59 \% ; n=49)$, and the need to improve the blood visualisation system through the cannula $(39.8 \% ; n=33)$.

Regarding nurses' perceptions of PC and their design characteristics, the most frequent response was "positive" with an average of $55.8 \%$, followed by the answer "I don't know" with $33.8 \%$ on average and finally, the "negative" response with an average of $10.3 \%$. The specific answers to each item are displayed in Table 4, showing that, of the six defining items, only the fact that the cannula does not have wings was rated as negative while the other items were rated positively.

The results of the comparison between conventional metal needles and plastic needles are presented in Table 5. Based on the experience and knowledge of the nurses surveyed, the most frequently reported response was "I don't know" with an average of 52.5\%, followed by the "less frequent" response with $32.3 \%$ on average and, finally, the "more frequent" response with $15.2 \%$ on average. From the list of possible complications presented, only the impossibility of a successful cannulation was highlighted as more frequent in PC compared with conventional metal needles. 
Finally, participants knowledge and experience of PC was assessed. The most frequent response was "I don't know" with an average of 59.5\%, followed by the "true" answer with $25 \%$ on average and finally, the "false" answer with an average of $15.5 \%$. These results are presented in Table 6 and are discussed more fully in the discussion section.

\section{DISCUSSION}

The most striking finding of this study was the low prevalence of the availability of PC and training in its use. PC are currently presented in the literature as a good alternative to conventional metal needles and as a product widely used in other countries of the world (Grainer 2014). However, this situation has not been reflected in the findings of the present study, which is an important bias recognized by the research team. Despite this, the finding is still significant and an important source of knowledge to continue working to improve the quality of care provided.

This study also found that PC are less frequently available in institutions with subsidised and private management. In addition, the availability of PC in units is directly related to training and use, with greater training and use of PC in those units where this produce is available. Thus, there may be a cause-result relationship; that is, nurses who do not have access to this type of needle do not, therefore, have the opportunity to receive the necessary training because they will not use them in their daily practice. The use and availability of healthcare materials have been explored in other studies concluding that consumption and use of materials are affected not only by their availability but also by their location and proximity (Torres-Quintana et al. 2015). Thus, the relationship between availability and use and training is basic in usual nursing practice and is a key element for designing improvements in established care plans. To achieve improvements, the availability of better materials (according to the scientific evidence) should be a requirement for professionals and mandatory for management.

Following analysis of the use and training of the product evaluated, almost half of these nurses admitted that they had never used PC. In addition, almost half of the total number of participants had never been trained in PC use. The concept of training, in the proposed use in this study, refers to having received intentional theoretical-practical education from a qualified professional. Following this concept, and according to the descriptive integrative description proposed by Rojas-Reyes et al. (2018), continuing nursing education (or training) is established as the basis for progress of the profession. Therefore, training ensures the preparation of competent nurses so that as a professional 
group, nursing will gain the visibility and social recognition that it deserves. Therefore, it is worth highlighting again the low prevalence of training among Spanish HD nurses in PC, which are presented in the literature as a beneficial innovation for people with a VAs requiring HD (Marticorena et al. 2018).

Analysis of nurses who had received training and who worked in centres where PC were available revealed that the training was provided mainly the industry producing the product or by peer mentoring. A very small percentage reported they had received training from a nurse expert in the product and field of study. This characteristic in which training is not provided by an expert nurse has been identified by Mousazadeh et al. (2018) as an element of professional distortion that can affect the training of the collective and the low level of attraction to the profession. According to these authors, encouraging professional and rigorous training by qualified nurses allows elimination of internal barriers in the profession and a move towards a standard in which professional identity and satisfaction are improved. In addition, the informants of this study recognised that the use of PC requires specific training and a learning period with support from expert nurses who have mastered the needling technique with these PC.

A substantial proportion of study participants had no training in PC. In addition, among those who had received training, it had not been performed equally among the participating nurses, impeding uniformity in the result. Current clinical practice guidelines on VA recommend that the use of metal needles be avoided and that more biocompatible materials be used (Queensland Government 2015). Our results indicate that this recommendation is not being implemented in Spanish HD units for the reasons stated: nurses do not have these materials available and do not have proper training in their use.

Analysis of the impressions of PC among the surveyed nurses showed that they rated the characteristics of the product highly. Other countries, such as Japan and Australia, have extensive experience in the use of this product and it has become the material of choice to puncture all types of VA for patients undergoing HD (Nalesso et al. 2018). Although the innovative characteristics of the product have been extensively reviewed and it has been presented as the best alternative for specific groups of patients with special characteristics (metal allergy, cognitive deterioration, restless legs syndrome, children, patients on nocturnal or long-term HD programmes, etc.) (Nalesso et al. 2018), it has also been shown that most patients on HD can benefit with equal or better results than those obtained with conventional needles. Indeed, previous studies have compared the 
innovative features of PC with metal needles and have concluded that PC provide major advantages for both the patient as well as the survival and care of the VAs (Smith \& Schoch 2016; Parisotto et al. 2016).

This study also assessed the characteristics of PC and nurses' perception of them [Tables 5 and 6] and found that, although nurses would include modifications or improvements to the current product design [Table 3], their defining characteristics, extracted from documented scientific knowledge in the literature, were rated positively by most participants [Table 4].

More than a half of the sample reported positive characteristics versus a small percentage who reported negative characteristics. Of the six defining items of this product [Table 4], only the lack of catheter wings to achieve a better grip and fixation in the skin was considered a negative characteristic by a majority of participants. Likewise, this characteristic is mentioned in the proposals for improvement [Table 3] in which most of the nurses who had used PC at some time would add wings to the cannula to allow better grip and fixation. Other proposals for improvement were adding a clamp to the system and enhancing the blood visualisation system when the needle enters the access port.

Of note, these proposals for improvement were made by users of the product. Previous studies have shown that proposals by users can be highly effective in enhancing the product (Smith et al. 2019). Other studies argue that the product design is not the variable of greatest interest in terms of cannulation (being rated below other variables such as years of nurses' experience, confidence of the phlebotomist or patient characteristics) (Carr et al. 2019). However, the improvements proposed in this study were supported by a majority of participating nurses.

Another important finding was that the participating nurses validated the theories on the best care of VA and improvements for HD treatment [Tables 5 and 6]. According to the responses to this part of the evaluation, the nurses' agreed with the scientific basis presented (Smith \& Schoch 2017, Letachowicz et al. 2015) and validated it through their statements, which are based on their experiences and knowledge. Agreement between the perception of nurses and the results in the scientific literature encourages the use of this product in daily clinical practice, with the main objective of improving the care of persons with CKD and VAs. 


\section{Study limitations}

This study was conceived as a first approach to understanding the current situation of nurses' use and experience of PC. The main limitation of this study is its quantitative design, which could be minimised in future by a qualitative approach more closely focused on perceptions of the design of the product.

In addition, the small sample size, in relation to the study population, may have influenced the results. As well, the convenience sampling method and the methodology used has not allowed to achieve great representativeness of the study population. For this reason, it would be important, in future research, to achieve greater representativeness. Despite this limitations, this study is presented as a first exploration that has provided sufficient findings for its dissemination and allows us to continue delving into the field of the study.

Another thing to consider is the low prevalence of availability and training on the evaluated product. This has caused obvious problems in interpreting the results. Despite this, this point has been considered the most important finding and has been preserved as an interesting result to report. Identifying negative or improvement points and reporting them will allow us to continue adding quality on the care provided.

\section{Implications for practice}

The results of this study could be of interest to enhance the care of persons with CKD under HD treatment with VA. According to the findings in the literature, PC are the best option for the care of VA but are not yet widely used in Spanish centres. Based on the evidence presented and available, if we manage to integrate this knowledge and work on the continuum of achieving excellence, we will continue to grow as a profession and provide higher quality care. In this way, it is essential to approach training strategies for nurses and thus increase knowledge about these products that have widely shown their benefits.

In addition, ratings of the product design could help to improve it and adapt it to users' needs. The evaluation of products must be led by the professionals involved and this will make it truly adapt to real needs, awakening the interest of its potential users. This will increase nurses' interest in the product and transfer it to daily practice, with the benefits for the AV and the person already exposed. 


\section{CONCLUSIONS}

PC are rated highly by Spanish HD nurses, but these needles are not available to a substantial number of nurses who, in addition, have not received the necessary training in their use. In contrast, the nurses in this study reported that the product's characteristics could be improved and some rated it negatively. Therefore, it would be interesting to include nurses in a working group to review the product's characteristics.

PC are not uniformly available in institutions, which may affect the quality of care received by patients in distinct centres. 


\section{REFERENCES}

Boletín Oficial del Estado. (2018). Ley Orgánica 3/2018, de 5 de diciembre, de Protección de Datos Personales y garantía de los derechos digitales [Protection of Personal Data and guarantee of digital rights]. Retrieved from: https://www.boe.es/eli/es/lo/2018/12/05/3/dof/spa/pdf

Carr P.J., Rippey J.C.R., Cooke M.L. et al. (2019). Factors associated with peripheral intravenous cannulation first-time insertion success in the emergency department. A multicentre prospective cohort analysis of patient, clinician and product characteristics. BMJ Open, 9(4), e022278.

European Parliament. Official Journal of the European Union. (2016). Regulation (EU) 2016/679 of the European Parliament and of the Council of 27 April 2016 on the protection of natural persons with regard to the processing of personal data and on the free movement of such data, and repealing Directive 95/46/EC (General Data Protection Regulation). Retrieved from: https://eur-lex.europa.eu/legalcontent/EN/TXT/PDF/?uri=CELEX:32016R0679\&from=EN

Fulker D., Sayed Z., Simmons A. et al. (2017). Computational Fluid Dynamic Analysis of the Hemodialysis Plastic Cannula. Artif Organ, 41(11), 1035-1042.

Grainer F. (2014). Plastic (non-metal) fistula cannula: from concept to practice. Ren Soc Australas J, 10, 44-46.

Ibeas J., Roca-Tey R., Vallespín J. et al. (2017). Spanish Clinical Guidelines on Vascular Access for Haemodialysis. Nefrologia, 37(1), 1-191.

Letachowicz K., Kusztal M., Gołębiowski T. et al. (2015). Use of Plastic Needles for Early Arteriovenous Fistula Cannulation. Blood Purif, 40(2), 155-159.

Marticorena R.M., Dacouris N., Donnelly S.M. (2018). Randomized pilot study to compare metal needles versus plastic cannulae in the development of complications in hemodialysis acces. J Vas C Access, 19(3), 272-282.

Mousazadeh S., Yektatalab S., Momennasab M. et al. (2018). Impediments to the formation of intensive care nurses' professional identify. Nurs Ethics, 26(6), 18731885 .

Nalesso F., Garzotto F., Muraro E., et al. (2018). Fistula cannulation with a novel fistula cannula: A review of cannulation devices and procedures. Blood Purif, 45, 278-283.

National Kidney Foundation. (2016). Needles and cannulas for arteriovenous fistula access: more options promote better outcomes. Retrieved from: https://www.kidney.org/sites/default/files/Fistula\%20Bulletin_0.pdf

Parisotto M.T., Pelliccia F., Bedenbender-Stoll E. et al. (2016). Haemodialysis plastic cannulae: A posible alternative to traditional metal needles? J Vac Access, 17(5), 373-379. 
Parisotto M.T., Schoder V.U., Miriunis C. et al. (2014). Cannulation technique influences arteriovenous fistula and graft survival. Kidney Int, 86(4), 790-797.

Queensland Government. Department of Health. (2015). Guideline: Peripheral intravenous catheter (PIVC). Retrieved from: https://www.health.qld.gov.au/_data/assets/pdf_file/0025/444490/icare-pivcguideline.pdf

Rojas-Reyes J., Rivera-Álvarez L.N., Morera-Pomarede M.J. (2018). Pedagogic Aspects in Nursing Education: Integrative Review. Invest Educ Enferm, 36(3), e03.

Shi K., Jiang H., Wakabayashi M. (2020). Effect of Early Cannulation with Plastic Cannula on Arteriovenous Fistula Patency in Hemodialysis Patients. Blood Purif, 49(1-2), 79-84.

Smith N., Hunter K.F., Rajabali S., et al. (2019). Where do women with urinary incontinence find information about absorbent products and how useful do they find it? J Wound Ostomy Continence Nurs, 46(1), 44-50.

Smith V., Schoch M. (2017). Do plastic cannulae have better outcomes than metal needles in haemodialysis? A retrospective review. Renal Society of Australasia Journal, 13(3), 78-82.

Smith V., Schoch M. (2016). Plastic cannula use in hemodialysis access. J Vasc Access, 17(5), 405-410.

Torres-Quintana A., Icart-Isern M.T., Esquinas-López C. (2015). Impact of lateralitylocation in the consumption of health products in a hemodialysis unit. Rev Enferm. 38(9), 16-21. 


\section{TABLES}

Table 1. Sociodemographic characteristics of the sample

\begin{tabular}{|c|c|c|}
\hline $\operatorname{Sex}(\% ; n)$ & $\begin{array}{r}\text { Women } \\
\text { Men }\end{array}$ & $\begin{array}{l}87.7 \%(143) \\
12.3 \%(20)\end{array}$ \\
\hline Mean age (SD) & \multicolumn{2}{|c|}{$42.4 \pm 9.97$ years } \\
\hline $\begin{array}{r}\text { List of participating } \\
\text { provinces }(\% ; \mathbf{n})\end{array}$ & $\begin{array}{r}\text { Barcelona } \\
\text { Madrid } \\
\text { Valencia } \\
\text { Murcia } \\
\text { Tarragona } \\
\text { Sevilla } \\
\text { Valladolid } \\
\text { Almería } \\
\text { Castellón } \\
\text { Córdoba } \\
\text { Málaga } \\
\text { Zaragoza } \\
\text { Illes Balears } \\
\text { A Coruña } \\
\text { Asturias } \\
\text { Lleida } \\
\text { Santa Cruz de Tenerife } \\
\text { Vizcaya } \\
\text { Álava } \\
\text { Albacete } \\
\text { Alicante } \\
\text { Badajoz } \\
\text { Cantabria } \\
\text { Cuenca } \\
\text { Girona } \\
\text { Granada } \\
\text { Guadalajara } \\
\text { La Rioja } \\
\text { Las Palmas } \\
\text { León } \\
\text { Melilla } \\
\text { Navarra } \\
\text { Ourense } \\
\text { Palencia } \\
\text { Salamanca } \\
\text { Segovia }\end{array}$ & $\begin{array}{l}30.7 \%(50) \\
19.6 \%(32) \\
4.9 \%(8) \\
3.7 \%(6) \\
3.7 \%(6) \\
3.1 \%(5) \\
3.1 \%(5) \\
2.5 \%(4) \\
2.5 \%(4) \\
2.5 \%(4) \\
2.5 \%(4) \\
2.5 \%(4) \\
1.8 \%(3) \\
1.2 \%(2) \\
1.2 \%(2) \\
1.2 \%(2) \\
1.2 \%(2) \\
1.2 \%(2) \\
0.6 \%(1) \\
0.6 \%(1) \\
0.6 \%(1) \\
0.6 \%(1) \\
0.6 \%(1) \\
0.6 \%(1) \\
0.6 \%(1) \\
0.6 \%(1) \\
0.6 \%(1) \\
0.6 \%(1) \\
0.6 \%(1) \\
0.6 \%(1) \\
0.6 \%(1) \\
0.6 \%(1) \\
0.6 \%(1) \\
0.6 \%(1) \\
0.6 \%(1) \\
0.6 \%(1)\end{array}$ \\
\hline $\begin{array}{r}\text { Types of institution } \\
(\% ; n)\end{array}$ & $\begin{array}{l}\text { Public institution } \\
\text { Subsidised institution } \\
\text { Private institution }\end{array}$ & $\begin{array}{l}61.4 \%(100) \\
30.7 \%(50) \\
7.9 \%(13)\end{array}$ \\
\hline $\begin{array}{l}\text { Years (median) of } \\
\text { experience in HD }\end{array}$ & 15 years $\left[\mathrm{P}_{25} 8\right.$ & $\left.\mathrm{P}_{75} 22\right]$ \\
\hline
\end{tabular}


Table 2. Professionals' satisfaction with pc and professional's perception of patients' satisfaction with pc.

\begin{tabular}{|r|l|r|l|}
\hline \multicolumn{2}{|c|}{ Professionals' satisfaction with PC (\%; n) } & $\begin{array}{r}\text { Professionals' perception of patients' satisfaction } \\
\text { with PC (\%; n) }\end{array}$ \\
\hline Very satisfied & $9.2 \%(15)$ & Very satisfied & $6.1 \%(10)$ \\
\hline Satisfied & $25.2 \%(41)$ & Satisfied & $16.6 \%(27)$ \\
\hline Indifferent & $7.9 \%(13)$ & Indifferent & $17.8 \%(29)$ \\
\hline Dissatisfied & $7.4 \%(12)$ & Dissatisfied & $3.1 \%(5)$ \\
\hline Very dissatisfied & $1.2 \%(2)$ & Very dissatisfied & $1.2 \%(2)$ \\
\hline Not applicable, I have never used them & $49.1 \%(80)$ & Not applicable. we do not use them & $55.2 \%(90)$ \\
\hline
\end{tabular}


Table 3. Professionals who have used PC (50.9\%; $n=83)$ suggested the following modifications (point 16 of the questionnaire).

\begin{tabular}{|r|l|}
\hline & $(\mathbf{( \% )} \mathbf{n})$ \\
\hline I would add a system to clamp the cannula & $59 \%(49)$ \\
\hline I would add wings to the cannula for better grip and fixation & $74.7 \%(62)$ \\
\hline I would eliminate the anti-reflux valve & $0 \%(0)$ \\
\hline I would shorten the length of the catheter & $6 \%(5)$ \\
\hline I would increase catheter length & $20.5 \%(17)$ \\
\hline I would modify the needle safety system & $8.4 \%(7)$ \\
\hline I would improve the blood visualisation system through the cannula & $39.8 \%(33)$ \\
\hline I would decrease the needle gauge & $12.1 \%(10)$ \\
\hline I would increase the needle gauge & $7.2 \%(6)$ \\
\hline Nothing & $9.6 \%(8)$ \\
\hline Other: Having the possibility to recanalize & $8.4 \%(7)$ \\
\hline
\end{tabular}


Table 4. According to your experience and knowledge, choose the proper answer regarding the design and characteristics of PC (100\%; $n=163$ ) (point 17 of the questionnaire).

\begin{tabular}{|c|c|c|c|}
\hline & $\begin{array}{l}\text { Positive } \\
(\% ; \mathbf{n})\end{array}$ & $\begin{array}{l}\text { Negative } \\
(\% ; n)\end{array}$ & $\begin{array}{l}\text { I don't know } \\
(\% ; \mathbf{n})\end{array}$ \\
\hline $\begin{array}{r}\text { PC do not have wings; they are not designed as a butterfly- } \\
\text { shaped catheter }\end{array}$ & $9.2 \%(15)$ & $52.2 \%(85)$ & $38.7 \%(63)$ \\
\hline $\begin{array}{r}\text { PC have an anti-reflux valve that prevents blood dripping even } \\
\text { after the needle is removed }\end{array}$ & $67.5 \%(110)$ & $0.6 \%(1)$ & $31.9 \%(52)$ \\
\hline $\begin{array}{l}\text { A needle is required for the puncture but, at the end, only a } \\
\text { plastic catheter is allocated }\end{array}$ & $66.3 \%(108)$ & $1.2 \%(2)$ & $32.5 \%(53)$ \\
\hline PC have an anti-puncture security system & $60.7 \%$ (99) & $3.7 \%(6)$ & $35.6 \%(58)$ \\
\hline $\begin{array}{l}\text { PC have a system that allows visualisation of the blood in the } \\
\text { needle which allows us to see that the blood has reached the vein }\end{array}$ & $64.4 \%(105)$ & $3.7 \%(6)$ & $31.9 \%(52)$ \\
\hline $\begin{array}{r}\text { PC are a bio-compatible product that guarantee an alternative to } \\
\text { allergic metal patients }\end{array}$ & $66.9 \%(109)$ & $0.6 \%(1)$ & $32.5 \%(53)$ \\
\hline
\end{tabular}


Table 5. Compared to conventional metal needles, do you think these assumptions are more or less frequent? (100\%; $n=163)$ (point 18 of the questionnaire).

\begin{tabular}{|r|c|c|c|}
\hline & $\begin{array}{c}\text { More frequent } \\
(\% ; \mathbf{n})\end{array}$ & $\begin{array}{c}\text { Less frequent } \\
(\% ; \mathbf{n})\end{array}$ & $\begin{array}{c}\text { I don't know } \\
(\% ; \mathbf{n})\end{array}$ \\
\hline Pain & $17.8 \%(29)$ & $28.8 \%(47)$ & $53.4 \%(87)$ \\
\hline Longer compression time & $7.9 \%(13)$ & $32.5 \%(53)$ & $59.5 \%(97)$ \\
\hline Access extravasations & $8.6 \%(14)$ & $47.9 \%(78)$ & $43.6 \%(71)$ \\
\hline $\begin{array}{r}\text { Impossibility of successful } \\
\text { cannulation }\end{array}$ & $27 \%(44)$ & $16 \%(26)$ & $57.1 \%(93)$ \\
\hline Larger crusts & $22.7 \%(37)$ & $23.9 \%(39)$ & $53.4 \%(87)$ \\
\hline Bruises & $6.1 \%(10)$ & $46 \%(75)$ & $47.9 \%(78)$ \\
\hline Accidental needle removal & $16 \%(26)$ & $31.3 \%(51)$ & $52.8 \%(86)$ \\
\hline
\end{tabular}


Table 6. Based on your experience and knowledge, mark the following statements if the answer is true or false (100\%; $n=163)$ (point 19 of the questionnaire).

\begin{tabular}{|c|c|c|c|}
\hline & $\begin{array}{l}\text { True } \\
(\% ; \mathbf{n})\end{array}$ & $\begin{array}{l}\text { False } \\
(\% ; n)\end{array}$ & $\begin{array}{l}\text { I don't know } \\
(\% ; \mathbf{n})\end{array}$ \\
\hline $\begin{array}{r}\text { Dialysis with a PC shows a better hemodynamic profile } \\
\text { than those made with metallic needles }\end{array}$ & $9.8 \%(16)$ & $21.5 \%(35)$ & $68.7 \%(112)$ \\
\hline $\begin{array}{l}\text { PC provide better results in the arterial and venous } \\
\text { pressures and the final efficiency of the session }\end{array}$ & $20.9 \%(34)$ & $17.8 \%(29)$ & $61.4 \%(100)$ \\
\hline PC lower arterial needle pressure & $16.6 \%(27)$ & $21.5 \%(35)$ & $62 \%(101)$ \\
\hline PC increase venous needle pressure & $7.9 \%(13)$ & $31.9 \%(52)$ & $60.1 \%(98)$ \\
\hline PC offer less mechanical trauma on the vascular access & $33.7 \%(55)$ & $12.9 \%(21)$ & $53.4 \%(87)$ \\
\hline $\begin{array}{r}\text { PC allow heparin dose reduction without worsening } \\
\text { coagulation control of the dialyzer and the state of the } \\
\text { arterial and venous chambers }\end{array}$ & $4.3 \%(7)$ & $22.7 \%(37)$ & $73 \%(119)$ \\
\hline $\begin{array}{r}\text { PC are as effective as metal needles in dialysis adequacy } \\
\text { and show a significant improvement in the number of } \\
\text { dialyzed litres, number of episodes of flow collapse and } \\
\text { session effectiveness. }\end{array}$ & $25.8 \%(42)$ & $11.7 \%(19)$ & $62.6 \%(102)$ \\
\hline $\begin{array}{r}\text { PC show a reduction in vascular complications and } \\
\text { decrease the haemostasis time }\end{array}$ & $38.7 \%(63)$ & $6.1 \%(10)$ & $55.2 \%(90)$ \\
\hline PC puncture is more painful & $17.2 \%(28)$ & $23.3 \%(38)$ & $59.5 \%(97)$ \\
\hline $\begin{array}{r}\text { PC use requires a period of learning by the nurse who } \\
\text { carries it out }\end{array}$ & $54 \%(88)$ & $2.5 \%(4)$ & $43.6 \%(71)$ \\
\hline Patient satisfaction with the catheter needle is higher & $20.3 \%(33)$ & $11 \%(18)$ & $68.7 \%(112)$ \\
\hline $\begin{array}{l}\text { PC are of choice in patients with a high probability of } \\
\text { suffering an extravasation, as well as for patients who } \\
\text { are disoriented and cannot leave the arm immobilized } \\
\text { during the session }\end{array}$ & $50.9 \%(83)$ & $3.1 \%(5)$ & $46 \%(75)$ \\
\hline
\end{tabular}




\section{APPENDIX}

Appendix 1. Ad hoc questionnaire.

\section{PART I. INFORMED CONSENT}

1. Email address:

2. I am a nurse working with people who require renal replacement therapy in the form of haemodialysis.

$\square$ Yes

3. Participation in the study

$\square$ I accept, freely and correctly informed, to participate in this study on the use of and satisfaction with plastic cannulas

\section{PART II. SOCIODEMOGRAPHIC DATA}

4. Gender: $\square$ Female $\square$ Male $\square$ I prefer not to say

5. Age:

6. Working province $\square$ A Coruña $\square$ Álava $\square$ Albacete $\square$ Alicante $\square$ Almería $\square$ Asturias $\square$ Ávila Badajoz $\square$ Islas Baleares $\square$ Barcelona $\square$ Burgos $\square$ Cáceres $\square$ Cádiz $\square$ Cantabria $\square$ Castellón

Ceuta $\square$ Ciudad Real $\square$ Córdoba $\square$ Cuenca $\square$ Girona $\square$ Granada $\square$ Guadalajara

$\checkmark$ Guipúzcoa $\square$ Huelva $\square$ Huesca $\square$ Jaén $\square$ La Rioja $\square$ Las Palmas $\square$ León $\square$ Lleida

Lugo $\square$ Madrid $\square$ Málaga $\square$ Melilla $\square$ Murcia $\square$ Navarra $\square$ Orense $\square$ Palencia

$\square$ Pontevedra $\square$ Salamanca $\square$ Segovia $\square$ Sevilla $\square$ Soria $\square$ Tarragona $\square$ Santa Cruz de Tenerife $\square$ Teruel

Toledo $\square$ Valencia $\square$ Valladolid $\square$ Vizcaya $\square$ Zamora $\square$ Zaragoza

7. Type of institution: $\square$ Public institution $\square$ Subsidised institution $\square$ Private institution

8. Years of experience in haemodialysis:

\section{PART III. EXPERIENCE OF USE WITH PLASTIC CANNULAS (PC)}

9. Do you have PC in your workplace? $\square$ Yes $\square$ No

10. Have you ever used PC? $\square$ Yes $\square$ No

11. Have you ever received training in the use of $\mathrm{PC}$ ?

Yes, in another workplace or in a congress (outside my workplace)

$\checkmark$ Yes, in my workplace and with the patients I work with every day

$\square$ No

12. If you have received training, it was provided by:

Commercial or industry representative

An expert nurse in the use of the PC

A colleague from the same workplace

13. Would you like to receive formal training in the use of PC?

$\square$ Yes, I am interested

$\square$ No, I have no interest

No, it is not necessary because I have already mastered it

Other: 
14. Indicate your overall satisfaction with plastic cannulas from 1 (very dissatisfied) to 5 (very satisfied).

1 (very dissatisfied) $\square 2$ (dissatisfied) $\square 3$ (indifferent)

$\square 4$ (satisfied) $\square 5$ (very satisfied) $\square$ Not applicable, I have never used them

15. State your level of satisfaction that you think the patient has with PC from 1 (very dissatisfied) to 5 (very satisfied)
$\square 1$ (very dissatisfied) $\square 2$ (dissatisfied) $\square 3$ (indifferent)
4 (satisfied) $\square 5$ (very satisfied) $\square$ Not applicable, I have never used them

16. What aspects of $P C$ would you modify?
$\square$ I would add a system to clamp the cannula
$\square$ I would add wings to the cannula for better grip and fixation
$\square$ I would eliminate the anti-reflux valve
I would shorten the length of the catheter
$\square$ I would increase catheter length
I would modify the needle safety system
I would improve the blood visualisation system through the cannula
I would decrease the needle gauge
$\square$ I would increase the needle gauge
Nothing
Other:

17. According to your experience and knowledge, choose "positive", "negative" or "I don't know", regarding the design and characteristics of $\mathrm{PC}$.

$$
\text { Positive Negative } \quad \begin{gathered}
\text { I don't } \\
\text { know }
\end{gathered}
$$

PC do not have wings; they are not designed as a butterfly-shaped

catheter

PC have an anti-reflux valve that prevents blood dripping even after the needle is removed

A needle is required for the puncture but, in the end, only a plastic catheter is allocated

PC have anti-puncture security system

PC have a system that allows visualisation of the blood in the needle, through which, when puncturing, the nurse can see that it has reached the vein

PC are a biocompatible product that guarantee an alternative to patients with metal allergy

18. Compared to conventional metal needles, do you think these elements are more frequent or less frequent?

$$
\text { More frequent Less frequent I don't know }
$$

Pain

Longer compression time

Access extravasations

Impossibility of successful

cannulation

Larger crusts

Bruises

Accidental needle removal 


\section{In your experience, mark the following statements as true or false}

True False I don't

Dialysis with a PC shows a better hemodynamic profile than those made with metal needles

PC provide better results in the arterial and venous pressures and the final efficiency of the session

PC lower arterial needle pressure

PC increase venous needle pressure

PC offer less mechanical trauma on the vascular access

PC allow a reduction in heparin dose without worsening the coagulation control of the dialyser and the state of the arterial and venous chambers

PC are as effective as metal needles in dialysis adequacy and show a significant improvement in the number of dialysed litres, number of episodes of flow collapse and session effectiveness

PC show a reduction in vascular complications and decrease the haemostasis time

PC puncture is more painful

$\mathrm{PC}$ use requires a period of learning by the nurse who carries it out

Patient satisfaction with the catheter needle is higher

PC are of choice in patients with a high probability of suffering an extravasation, as well as in patients who are disoriented and cannot leave the arm immobilised during the session 